\title{
ANÁLISE DO SISTEMA DE TROCA DE LÂMINAS DE CORTE EM COLHEDORA DE CANA-DE-AÇÚCAR
}

\author{
Márcio Rodrigues Saldeira" \\ Gislaine Camila Lapasini Leal** \\ Syntia Lemos Cotrim*** \\ Franciele Cristina Fenerich ${ }^{* * * *}$ \\ Edwin Vladimir Cardoza Galdamez ${ }^{* * * * *}$
}

RESUMO: A área de cana-de-açúcar colhida mecanicamente tem crescido a cada ano, a adoção deste sistema tem exigido das usinas controle rigorosos sobre seus equipamentos, principalmente com as colhedoras. As lâminas de corte da colhedora são substituídas ou invertidas conforme seu desgaste, operação que demanda mão de obra qualificada e tempo de máquina parada. Neste artigo foram analisados três métodos disponíveis para a troca ou inversão das lâminas do corte de base, o objetivo foi aumentar a disponibilidade da máquina para proporcionar maior produção a partir do índice de desempenho Overall Equipament Effectivences e a Troca Rápida de Ferramentas. Os resultados obtidos apontam que o Sistema de Troca Rápida possibilitou aumentar a disponibilidade dos equipamentos em 347 minutos, gerando um incremento na produção de 115,9 toneladas/dia. Foram coletadas e analisadas amostras de tempos em três turnos de trabalho com cada um dos sistemas testados. Para proporcionar melhor desempenho ao operador, também, foram analisados aspectos relacionados à adaptação ao manuseio de ferramentas, esforço e fadiga do operador, logística de peças e ferramentas.

PALAVRAS-CHAVE: OEE; Colhedora de cana; Lâminas de corte.

\section{ANALYZING THE BLADE EXCHANGE SYSTEM IN SUGAR-CANE HARVESTING MACHINES}

ABSTRACT: Machine-based sugar-cane harvest has been on the increase and its use requires strict control on equipments, especially, harvesting machines. Blades are

* Usina Santa Terezinha

** Doutora em Engenharia Elétrica e Informática Industrial; Docente do Departamento de Engenharia de Produção da Universidade Estadual de Maringá (UEM), Departamento de Engenharia de Produçã̃o (DEP), Brasil.

*** Universidade Estadual de Maringá, Departamento de Engenharia de Produção (DEP), Brasil; E-mail: slcotrim2@uem.br

**** Universidade Estadual de Maringá, Departamento de Engenharia de Produção (DEP), Brasil.

***** Doutor em Engenharia de Produção; Docente Associado do Departamento de Engenharia de Produção (DEP) da Universidade Estadual de Maringá (UEM), Brasil. 
replaced or inverted according to wear and tear, requiring specialized labor and loss of machine time. Current paper discusses three methods for blade exchange or inversion so that availability of the machine would be increased for better production through the Overall Equipment Effectiveness performance and Rapid Tool Replacement. Results showed that Rapid Tool Replacement increased the availability of the equipments for 347 minutes, with production increase of 115.9 tons/day. Time samples were collected and analyzed in three shifts with each tested system. Aspects related to the adaptation of tools used, effort and fatigue, logistics of spare parts and tools were assessed for the improvement of the machine operator.

KEY WORDS: OEE; Sugar-cane harvesting machines; Blades.

\section{INTRODUÇÃO}

A cana-de-açúcar é economicamente um dos mais importantes cultivos do Brasil, sendo o maior produtor mundial o país ocupa uma área de aproximadamente 8,810 milhões de hectares e 671,7 milhões de toneladas a serem industrializadas, para a safra de 2013-2014, (COMPANHIA NACIONAL DE ABASTECIMENTO CONAB, 2013). Para industrializar esta produção é necessário colher a matéria-prima no campo e transportá-la para a indústria (CERVI et al., 2015).

O sistema de colheita mecanizada da cana-de-açúcar foi desenvolvido a partir da necessidade de se realizar a colheita com maior capacidade operacional, melhorando a logística do corte e do carregamento e sua compatibilização com o ritmo da indústria (VOLTARELLI et al., 2014; RAMOS et al., 2015). Esse sistema tem sido constantemente discutido em vários aspectos, no que diz respeito às modificações necessárias para que haja melhoria na adequação entre as máquinas existentes no mercado e as particularidades dos canaviais de cada uma das unidades produtoras (VOLTARELLI et al., 2014).

Juntamente com o sistema de colheita mecanizada foram implantadas as colhedoras de cana-de-açúcar, equipamento de maior valor agregado onde é exigida grande produtividade, disponibilidade e eficiência para melhoria de seu desempenho operacional (FONTANA et al., 2004; MARQUES; SASSO, 2010). As colhedoras são responsáveis pelo corte mecanizado da cana-de-açúcar, isto ocorre 
por meio do corte basal dos colmos da cana-de-açúcar que é realizado a partir do impacto de diversas lâminas acopladas a discos rotativos que formam o conjunto dos cortadores de base, a limpeza parcial do material colhido é realizada por exaustores que separam a palha dos colmos cortados, os ponteiros são separados e lançados ao chão pelos cortadores de pontas e ainda há o fracionamento dos colmos por um conjunto de facões em rolos sincronizados dentro da máquina. Esse material é jogado diretamente em um caminhão (transbordo) que por sua vez transfere a canade-açúcar colhida para outro caminhão com maior capacidade de carga, para então a cana-de-açúcar ser transportada para a indústria (COELHO, 2009).

As colhedoras de cana-de-açúcar existentes no mercado estão em pleno desenvolvimento, adquirindo tecnologias que além de simplificar o processo de colheita para o operador, fornecem uma quantidade de dados que permitem melhorar o gerenciamento do que está sendo realizado no campo e principalmente, maximizam os ganhos com capacidade operacional, aproveitamento energético e qualidade do material colhido (VOLPATO, 2001). As inovações tecnológicas realizadas nas colhedoras proporcionam elevada produtividade e disponibilidade, além de contribuírem com a entrega de uma matéria-prima de acordo com as especificações da indústria, no entanto o estudo e adaptações de melhorias são constantes.

O uso do corte mecânico apresenta algumas peculiaridades relacionadas às interações máquina-planta durante a colheita, ocasionada pelo disco de corte basal onde as lâminas estão inseridas, que pode gerar danos à cultura da cana e provocar perdas na produção e perdas na qualidade. As colhedoras de cana-de-açúcar cortam os colmos em sua base pelo impacto de múltiplas lâminas montadas em dois discos rotativos. No corte por impacto, a força predominante é normal ao perfil da lâmina e causa grandes danos na soqueira e na cana colhida (MELLO, 2005).

O corte basal é um dos itens de maior importância nas colhedoras de cana, pois está diretamente ligado à qualidade da matéria-prima e aos níveis de perdas na colheita (CASSIA et al., 2014). A ausência dos recursos de flutuação independente por disco ao buscar o corte do colmo rente à superfície corta também grande quantidade de solo que é encaminhada ao interior da colhedora, com isto gera um aumento no índice de impurezas minerais e desgastes excessivos das lâminas de corte.

A manutenção inadequada das lâminas de corte basal podem aumentar significativamente a porcentagem de tocos e rebolos rachados e mal cisalhados, o 
que pode acarretar em perdas visíveis e invisíveis, prejudicando também as soqueiras que por consequência causa perdas de rebrota no canavial (NEVES, 2004). As lâminas do corte basal devem ser substituídas de acordo com seu desgaste ou mediante a necessidade de troca quando as facas apresentam suas extremidades arredondadas e sem corte, danificam as soqueiras causando perdas ao canavial. O sincronismo das facas dos discos de corte favorece a qualidade do corte e o aumento da vida útil do equipamento. O fato das lâminas de corte adquirir um formato arredondado após um determinado número de horas trabalhadas faz com que a cana deslize sobre o perfil da lâmina sem ser cortada adequadamente, forçando o operador a trabalhar com os discos do cortador de base abaixo da superfície do solo para evitar problemas na alimentação da máquina, gerando desgastes prematuros das lâminas (RIPOLI; RIPOLI, 2004; RIPOLI; RIPOLI, 2010).

Para manter uma boa produção a colhedora deve estar o maior tempo possível disponível para o operador executar a colheita, portanto o estudo de tempos e métodos pode ser definido como um estudo de sistema que possui pontos identificáveis de entrada - transformação - saída, estabelecendo padrões que facilitam as tomadas de decisões. Assim, pode-se favorecer o incremento da produtividade e prover-se de informações de tempos com o objetivo de analisar e decidir sobre qual o melhor método a ser utilizado nos trabalhos de produção (BARNES, 2008). Analisando as horas produtivas e improdutiva da máquina observou que a manutenção mecânica é fator fundamental no desempenho da colheita mecanizada. Isto é, realizando uma boa manutenção de reforma anual denominada manutenção de entre safra e manutenção preventiva adequada proporcionará um bom desempenho operacional aumentando a disponibilidade das máquinas para a colheita.

Molin (2003) preconiza que a eficiência de campo durante a operação de colheita é um importante parâmetro para determinar a capacidade de campo efetiva e, consequentemente, auxiliar na tomada de decisão a respeito do gerenciamento do sistema mecanizado, os quais por meio do mapa de produtividade possibilitam a obtenção de mapas de eficiência, capacidade de campo efetiva e capacidade de processamento. Desta forma é possível calcular as eficiências de campo, gerencial e global da operação. Na produção e na produtividade, a capacidade de colheita de 
colhedoras de cana está relacionada com a quantidade de trabalho que a máquina é capaz de executar na unidade de tempo, podendo ser efetiva, ou seja, aquilo que a máquina realmente produziu ou operacional que é a capacidade que a máquina pode produzir.

Desta modo, o objetivo deste artigo é analisar os sistemas de troca utilizados, por meio de metodologias propostas na Troca Rápida de Ferramentas (TRF), especificamente o indicador de Eficiência Global dos Equipamentos (OEE Overall Equipment Effectivenees), a fim de diminuir o tempo de troca ou inversão das lâminas de corte basal por meio de mecanismos que favoreçam o trabalho do operador e, com isto, aumentar o tempo de disponibilidade da máquina.

\section{MATERIAIS E MÉTODOS}

Este trabalho constitui na análise de três opções de troca ou inversão de lâminas de corte de base, o Sistema de Troca Tradicional proposto pelo fabricante do equipamento e comumente utilizado pelas Usinas; o Sistema de Troca Rápida, proposto para melhoria de ganho de tempo e o Sistema com Dispositivo de Troca Rápida Implantado que busca no auxílio de ferramentas específicas também ganho de tempo, cujas intervenções se baseiam em materiais - homem -máquina, todas as análises levaram em consideração o aproveitamento do tempo cuja finalidade foi de aumentar a disponibilidade da máquina.

A pesquisa conduzida é de natureza aplicada. Quanto à abordagem, a pesquisa é de caráter qualitativo e quantitativo. Em relação aos objetivos, trata-se de pesquisa exploratória, em que a análise dos dados foi realizada visando à ligação com os aportes teóricos. Para o cálculo de disponibilidade se analisou o tempo total de disponibilidade para a produção, tempo não tripulado e o tempo real de produção. No cálculo de desempenho foi analisada a velocidade nominal do equipamento, tempo de manobra e produção real do equipamento.

A pesquisa foi realizada em uma empresa do setor sucroenergético com frota de 16 colhedoras de cana, onde o operador da máquina ao realizar a operação de troca ou inversão dos lados das lâminas do corte de base utiliza-se apenas de 
ferramentas manuais. Ao realizar esta operação, o operador mantém a máquina parada por um determinado período. Observa-se que é fundamental fornecer métodos e ferramentas que possibilitem ao operador reduzir o tempo desta atividade. Neste sentido, foram analisados três sistemas de troca existentes (Sistema de Troca Tradicional, Sistema de Troca Rápida e Sistema com Dispositivo de Troca Rápida Implantado) com o intuito de compará-los em relação à disponibilidade (tempo) e produtividade.

O Sistema de Troca Tradicional (STT) composto por disco, lâminas, parafuso, porca e chave L $19 \mathrm{~mm}$, é o sistema padrão original do equipamento. No modelo tradicional, as lâminas são fixadas por parafusos e porcas de segurança com torque entre $80-110 \mathrm{Nm}$.

O Sistema de Troca Rápida (STR) é composto por disco adaptável, lâminas, chave apoio e chave batedor. Neste sistema as lâminas são fixadas em cunhas cônicas pelo encaixe do próprio disco de corte de base, realizado pelo impacto produzido pela chave específica.

O Sistema com Dispositivo de Troca Rápida Implantado (SDTR) é composto por disco, lâminas, parafuso, porca e chave de impacto pneumática, este sistema padrão original do equipamento, com auxílio de chave de impacto pneumática presente na oficina volante. Neste modelo as lâminas também são fixadas por parafusos e porcas de segurança com torque entre $80-110 \mathrm{Nm}$.

$\mathrm{O}$ equipamento utilizado para análise dos testes foi a Colhedora de Cana John Deere, modelo 3520, a qual possui um sistema composto original de fábrica composto por dois discos equipados com cinco lâminas cada um deles, sendo uma colhedora equipada com o sistema tradicional de troca original e outra equipada com o sistema de troca rápida, sendo que no sistema de troca original foram analisados o Sistema de Troca Tradicional (STT) e Sistema com Dispositivo de Troca Rápida Implantado (SDTR) com auxílio de oficina volante.

Os dados foram coletados na lavoura de colheita de cana-de-açúcar no momento em que o operador desativa a máquina para troca ou inversão dos lados das lâminas de corte. Neste período foram monitorados dados como tempo de troca ou inversão dos lados, adaptação a ferramentas, fadiga do operador e logística de peças, foram utilizados cronômetros para análise quantitativa de tempo e registros qualitativos. 
A coleta dos dados foi realizada "in loco" nos três turnos de trabalho (08 $\mathrm{h}$ cada). Conforme a necessidade de troca das lâminas os tempos foram tomados utilizando o cronômetro centesimal. Foram extraídas cinco amostras por turno de trabalho, totalizando 15 amostras realizadas para cada sistema.

Os dados coletados foram inseridos em planilhas eletrônicas que apoiaram a tomada de decisão mais assertiva juntamente com as análises qualitativas apresentadas para a melhoria da disponibilidade da colhedora, conforme detalhado no item 3.

\section{RESULTADOS E DISCUSSÃO}

Os sistemas de troca de lâminas apresentam alguns problemas, tanto na área operacional quanto na área administrativa. $\mathrm{Na}$ área operacional destaca-se a dificuldade do operador em retirar e fixar a lâmina de corte presa ao disco. Para a área administrativa aparece a falta de procedimentos e instrução de trabalho específico para a tarefa.

É importante ressaltar que o conceito de aumentar a disponibilidade do equipamento está relacionado ao nível de desempenho dos sistemas de troca ou inversão das lâminas, para analisar e visualizar cada um dos principais problemas no âmbito do indicador OEE, obtido a partir de três fatores: disponibilidade do equipamento para produzir (D), eficiência demonstrada durante a produção (E) e qualidade do produto obtido (Q) (CHIARADIA, 2004). Especificamente, foi elaborado um painel para avaliar os parâmetros de OEE, elencando os principais problemas encontrados no sistema de troca ou inversão de lâminas analisados, conforme Quadro 1.

Quadro 1. Problemas identificados na operação

(continua)

\begin{tabular}{|c|c|c|c|}
\hline $\begin{array}{c}\text { Parâmetro de } \\
\text { Desempenho }\end{array}$ & $\begin{array}{c}\text { Sistema de Troca } \\
\text { Tradicional (STT) }\end{array}$ & $\begin{array}{c}\text { Sistema de Troca } \\
\text { Rápida (STR) }\end{array}$ & $\begin{array}{c}\text { Sistema com } \\
\text { Dispositivo de Troca } \\
\text { Rápida Implantado } \\
\text { (SDTR) }\end{array}$ \\
\hline Disponibilidade & $\begin{array}{l}\text { Dificuldade de retirar } \\
\text { e fixar o parafuso }\end{array}$ & $\begin{array}{l}\text { Dificuldade de retirar a a } \\
\text { lâmina }\end{array}$ & $\begin{array}{l}\text { Disponibilidade do } \\
\text { veículo oficina volante }\end{array}$ \\
\hline
\end{tabular}


(conclusão)

\begin{tabular}{|c|l|l|l|}
\hline $\begin{array}{c}\text { Parâmetro de } \\
\text { Desempenho }\end{array}$ & $\begin{array}{l}\text { Sistema de Troca } \\
\text { Tradicional (STT) }\end{array}$ & \multicolumn{1}{|c|}{$\begin{array}{c}\text { Sistema de Troca } \\
\text { Rápida (STR) }\end{array}$} & $\begin{array}{l}\text { Sistema com } \\
\text { Dispositivo de Troca } \\
\text { Rápida Implantado } \\
\text { (SDTR) }\end{array}$ \\
\hline Produtividade & $\begin{array}{l}\text { Perdas por } \\
\text { movimento do } \\
\text { operador/Parada do } \\
\text { equipamento }\end{array}$ & $\begin{array}{l}\text { Perdas por movimento } \\
\text { do operador/Parada do } \\
\text { equipamento }\end{array}$ & $\begin{array}{l}\text { Parada do } \\
\text { equipamento/Espera } \\
\text { por terceiros/Perdas } \\
\text { por movimento do } \\
\text { operador }\end{array}$ \\
\hline Falta de qualidade & $\begin{array}{l}\text { Falta de treinamento } \\
\text { operacional/Instrução } \\
\text { de trabalho/Falta } \\
\text { de controle do } \\
\text { nível de torque/ } \\
\text { Falta de ferramenta } \\
\text { instrumento de } \\
\text { limpeza do disco }\end{array}$ & $\begin{array}{l}\text { Falta de treinamento } \\
\text { operacional/Instrução } \\
\text { de trabalho/Ferramenta } \\
\text { chave batedor requer } \\
\text { melhorias de apoio e } \\
\text { fixação }\end{array}$ & $\begin{array}{l}\text { Falta de treinamento } \\
\text { operacional/Instrução } \\
\text { de trabalho/Falta } \\
\text { de controle do } \\
\text { nível de torque/ } \\
\text { Falta de ferramenta } \\
\text { instrumento de } \\
\text { limpeza do disco }\end{array}$ \\
\hline
\end{tabular}

A Figura 1 apresenta a média dos tempos (em minutos) obtidos durante a troca das lâminas em cada turno e sistema.

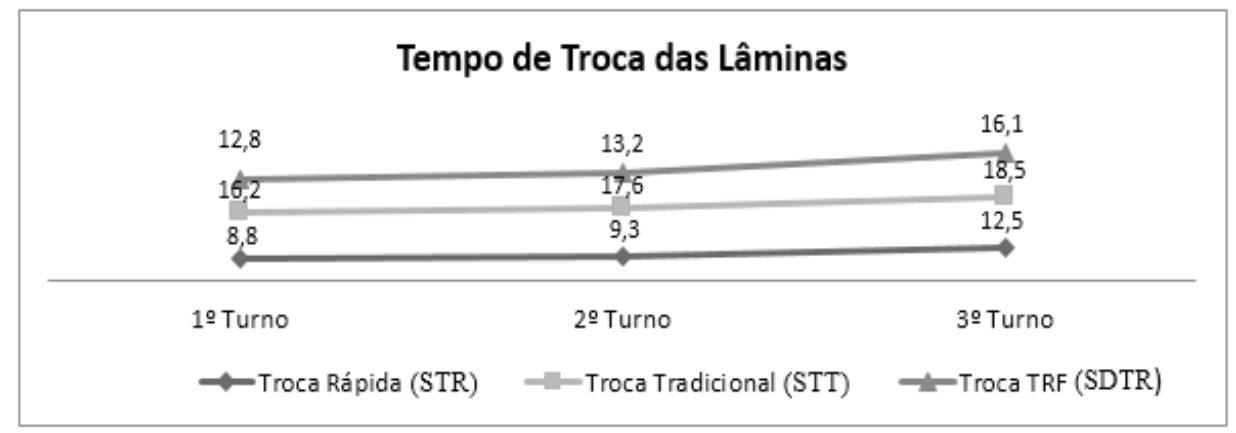

Figura 1. Comparação dos tempos de trocas em turnos

Nota se que o $2^{\circ}$ turno $(15 \mathrm{~h} 20 \mathrm{~min}-23 \mathrm{~h} 20 \mathrm{~min})$ e o $3^{\circ}$ turno $(23 \mathrm{~h} 20 \mathrm{~min}-$ 07h00) o tempo de troca aumentou em todas as opções de troca, isto ocorre devido às condições de tempo, pois o segundo turno pega uma parte do período noturno e o terceiro turno é desenvolvido em todo período noturno, sendo que neste período todas as atividades de manutenção em campo são prejudicadas pelas condições de 
visibilidade. No primeiro turno, desenvolvido durante o dia $(07 \mathrm{~h} 00-15 \mathrm{~h} 20 \mathrm{~min})$, as condições de visibilidade favorecem a colheita e a manutenção.

Em todas as atividades de troca verificou-se que mesmo em turnos diferentes o Sistema de Troca Rápida (STR) foi o mais vantajoso em comparado ao Sistema de Troca Tradicional (STT) e ao Sistema com Dispositivo de Troca Rápida Implantado (SDTR). A maior unidade de tempo gasto para atividade foi na retirada e colocação dos parafusos (STT) e (STDTR), já no sistema (STR) que excluiu o parafuso o tempo foi menor. Giachini (2012), avaliando o desempenho operacional de uma colhedora de cana-de-açúcar em diferentes turnos de trabalho, encontrou menores valores de perdas durante o turno $\mathrm{A}$, afirmando que as perdas aumentaram no turno $\mathrm{B}$ e foram maiores no turno $C$, sendo quantificadas em $0,92,1,6$ e 2,27 tha-1, respectivamente.

A Figura 2 mostra os tempos obtidos para cada uma das opções de troca, considerando os três turnos de trabalho.

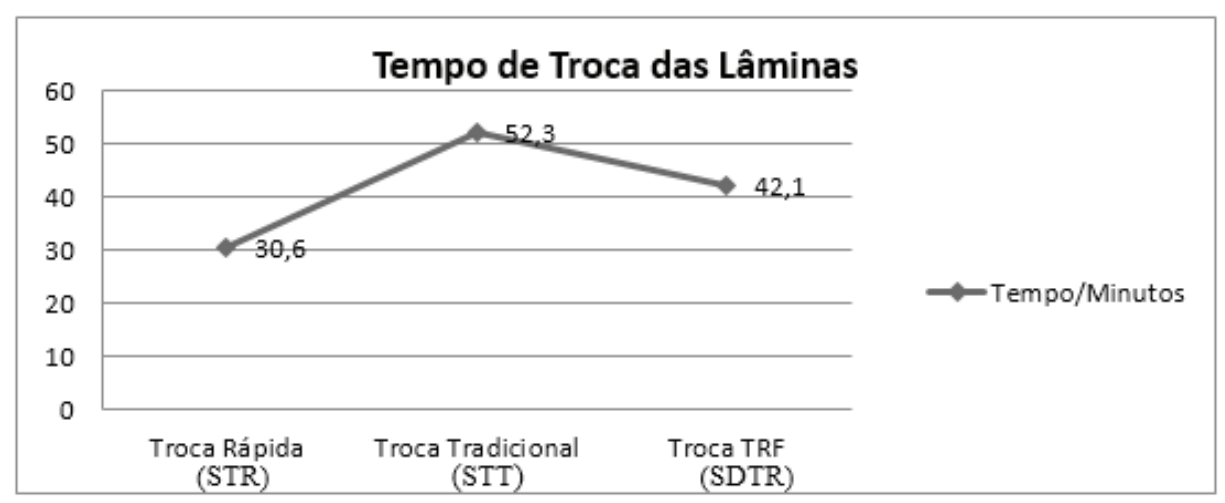

Figura 2. Comparação dos tempos de trocas por modelo

O Quadro 2 destaca os resultados obtidos na análise qualitativa de cada uma das opções de troca. 
Quadro 2. Diferenças entre os sistemas de troca

\begin{tabular}{|l|l|l|l|}
\hline Característica & \multicolumn{1}{|c|}{$\begin{array}{l}\text { Sistema de Troca } \\
\text { Tradicional (STT) }\end{array}$} & $\begin{array}{l}\text { Sistema de Troca Rápida } \\
\text { (STR) }\end{array}$ & $\begin{array}{l}\text { Sistema com } \\
\text { Dispositivo de Troca } \\
\text { Rápida Implantado } \\
\text { (SDTR) }\end{array}$ \\
\hline $\begin{array}{l}\text { Adaptação ao } \\
\text { manuseio de } \\
\text { ferramentas }\end{array}$ & $\begin{array}{l}\text { - Operadores adaptados às } \\
\text { ferramentas; } \\
\text { - Rotina diária; } \\
\text { - Conformidade com o } \\
\text { sistema. }\end{array}$ & $\begin{array}{l}\text { - Inovação; } \\
\text { - Facilidade no manuseio; } \\
\text { - Melhor encaixe e fixação. }\end{array}$ & $\begin{array}{l}\text { - Inovação; } \\
\text { - Auxilio mecânico; } \\
\text { - Dificuldade de } \\
\text { equilíbrio corporal. }\end{array}$ \\
\hline $\begin{array}{l}\text { Esforço/Fadiga } \\
\text { do Operador }\end{array}$ & $\begin{array}{l}\text { - Movimentos repetitivos; } \\
\text { - Postura ergonômica } \\
\text { inadequada; } \\
\text { - Esforço manual para } \\
\text { aperto. }\end{array}$ & $\begin{array}{l}\text { - Esforço manual para } \\
\text { encaixe; } \\
\text { - - Menor número de } \\
\text { movimentos; } \\
\text { - Maior força física do } \\
\text { operador. }\end{array}$ & $\begin{array}{l}\text { - Vibração; } \\
\text { - Exigência de postura } \\
\text { inadequada; } \\
\text { - Esforço físico. }\end{array}$ \\
\hline $\begin{array}{l}\text { Logística } \\
\text { das peças e } \\
\text { ferramentas }\end{array}$ & $\begin{array}{l}\text { - Fácil acesso; } \\
\text { - Facilidade na guarda e } \\
\text { conservação; } \\
\text { - Estoque para uso } \\
\text { imediato; } \\
\text { - Reposição frequente. }\end{array}$ & $\begin{array}{l}\text { - Facilidade nade guarda e } \\
\text { conservação; } \\
\text { - Estoque para uso } \\
\text { imediato; } \\
\text { - Reposição frequente. }\end{array}$ & $\begin{array}{l}\text { - Dificuldade de acesso; } \\
\text { - Problemas com } \\
\text { disponibilidade; } \\
\text { - Dependência de fatores } \\
\text { externos. }\end{array}$ \\
\hline
\end{tabular}

A utilização do indicador OEE, conforme proposto por esta metodologia, permite analisar as reais condições da utilização do equipamento com as metodologias de troca de lâminas apresentadas, estas análises das condições ocorrem a partir da identificação das perdas existentes, envolvendo índices de disponibilidade dos equipamentos, desempenho e qualidade, considerando o tempo total de produção, tempo não tripulado, paradas não planejadas e tempo real de produção para cálculo de disponibilidade (KWON; LEE, 2004; HANSEN, 2006).

Para cálculo de desempenho/eficiência foram considerados velocidade do equipamento, manobras/horas virando, produção nominal e produção real do equipamento. Para os índices de qualidade foram analisados os quesitos de desperdícios, perdas de matéria-prima, e produção total do equipamento. Na Figura 3 são apresentados os valores de OEE para cada uma das opções de troca de lâminas de corte. 


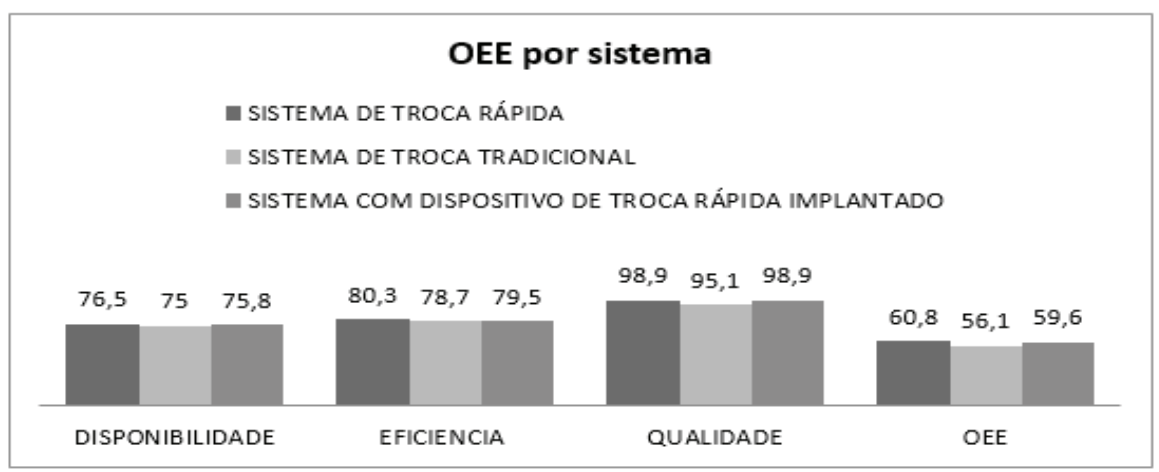

Figura 3. OEE por sistema

Confrontando os dados para uma frota composta por 16 colhedoras, comparado os sistemas de troca ou inversão das lâminas de corte STT/SDTR e STR observam-se ganhos no STR de disponibilidade de $05 \mathrm{~h} 47 \mathrm{~min}$, ou seja, 21,6 minutos/ dia por máquina. Além disso, há, também, um incremento na produção de 115,9 toneladas/dia, considerando uma produção diária inicial de 440 toneladas/dia, conforme apresentado na Figura 4.

Ganhos de Toneladas para a Frota (16 Colhedoras)

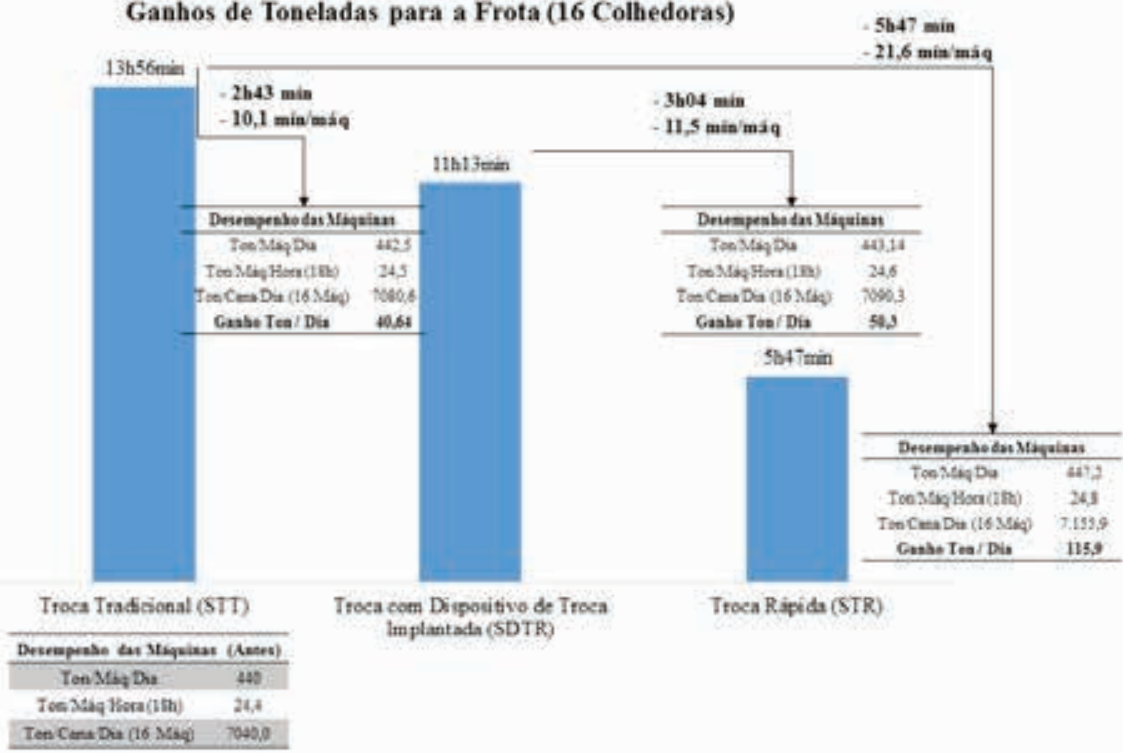

Figura 4. Ganhos de disponibilidade e produção para a frota 
A comparação entre os sistemas de troca com foco na redução do tempo de troca de lâminas de corte e aumento na disponibilidade do equipamento, a assertividade do método escolhido, confiabilidade, depende do atendimento às características mensuráveis de desempenho, eficiência e qualidade. Analisando todos os quesitos OEE e também a metodologia de TRF foi verificado que o método de troca de lâminas denominado Sistema de Troca Rápida (STR) foi o que mais apresentou aumento de ganho com disponibilidade, eficiência e qualidade, uma vez que o operador da máquina bem treinado para realizar a troca consegue realizá-la em tempo bem menor que ao Sistema de Troca Tradicional (ST'T).

O Sistema com Dispositivo de Troca Rápida Implantado (SDTR) apresenta grande dificuldade no campo, pois depende de meios e ferramentas mecânicas para sua utilização, o mecanismo de troca tradicional também não se mostrou eficiente perante os demais.

\subsection{ANÁLISE DE MELHORIA DO SISTEMA DE TROCA DE LÂMINAS DE CORTE}

Analisando os três sistemas de troca ou inversão das lâminas de corte de base propostos e a interação entre o operador e as ferramentas são propostas melhorias na adaptação de ferramentas, treinamento de operadores e sistema de logística de abastecimento e reposição de peças utilizadas - materiais de consumo.

Em relação ao Sistema de Troca Tradicional (STT) deve-se oferecer treinamento teórico e prático ao operador quanto aos quesitos de conhecimento e manuseio de ferramentas, metodologia de eficiência e disponibilidade do equipamento, segurança operacional e prática de campo, também deve se fornecer ferramental padronizado e de boa qualidade (lâminas de corte - chave e parafuso). Quanto à logística e reposição das lâminas, pode se instalar caixa de ferramentas no equipamento com compartimentos para guarda de ferramentas de troca, guarda de lâminas nova e local para lâminas substituídas, favorecendo estoque de peças, pois se observou que na maioria das vezes a oficina volante não está próximo ao equipamento no ato da troca ou inversão dos lados.

No Sistema de Troca Rápida (STR) deve-se oferecer treinamento teórico e prático ao operador quanto aos quesitos de conhecimento e manuseio de ferramentas 
especificas e metodologia de eficiência e disponibilidade do equipamento, segurança operacional e prática de campo, quanto ao ferramental deve se melhorar a chave de impacto, principalmente nos quesitos de segurança do operador aumentando a borda externa. Quanto à logística e reposição das lâminas pode se instalar caixa de ferramentas no equipamento com compartimentos específico para a guarda de ferramentas de troca, guarda de lâminas nova e local para lâminas substituíveis, favorecendo estoque de peças, pois se observou que na maioria das vezes a oficina volante não está próximo ao equipamento no ato da troca ou inversão dos lados.

Para o Sistema com Dispositivo de Troca Rápida Implantado (SDTR) deve se oferecer treinamento teórico e prático ao operador quanto aos quesitos de conhecimento e manuseio de ferramentas, metodologia de eficiência e disponibilidade do equipamento, segurança operacional e prática de campo, manter boa comunicação entre a colhedora e a oficina volante, estabelecer programa de parada para troca ou inversão das lâminas, estudar e analisar a possibilidade de instalação de chave pneumática de impacto nos tratores / caminhões transbordos.

É recomendável que se elabore a instrução de trabalho para detalhar cada um dos processos utilizados e facilitar operador no aprendizado de cada uma das ações, pois, conforme destacado por Santos (2007) é extremamente importante que existam os procedimentos adequados para manutenção de cada máquina da produção.

\section{CONSIDERAÇÕES FINAIS}

Em uma busca constante por eficiência, as empresas precisam considerar diversos fatores que impactam na produtividade de todo o ciclo de produção e um dos fatores que mais impactam na capacidade total são as máquinas e se elas param quando deviam estar em operação o negócio complica, pois não geram a produção que mantem o negócio (ZUASHKIANI, 2011).

Este artigo analisou três sistemas de troca de lâminas de corte de base em colhedoras de cana-de-açúcar, levando em consideração a metodologia de Troca Rápida de Ferramentas (TRF) e o índice OEE, em que foi possível evidenciar que o 
Sistema de Troca Rápida (STR) teve melhor viabilidade em comparação aos outros dois sistemas. Além disso, também, pode se verificar que o operador se adaptou melhor a este ferramental específico. O Sistema de Troca Rápida (STR) apresentou índice de disponibilidade, eficiência e qualidade superior aos demais, com isto aumentou a disponibilidade da máquina, o que refletiu em um incremento na produção de 115,9 Toneladas/dia.

Considerando a necessidade de melhoria contínua, seria oportuno salientar que há uma série de outros fatores relacionados ao tema deste trabalho, os quais necessitam de maior aprofundamento científico: sistema de manutenção e intervenção do operador (i.e., uma abordagem detalhada de todos os mecanismos que envolvem a interação homem-máquina), melhoria do sistema de preparo do solo, plantio e manejo para facilitar a colheita mecanizada da cana-de-açúcar.

Dentre os aspectos analisados o que apresenta maior vulnerabilidade e que detém grande potencial de avanços tecnológicos são as colhedoras de cana-de-açúcar. Estas devem ser alvos de estudos de melhoria e inovação. Como oportunidades de trabalhos futuros destaca-se a implantação da metodologia SMED (Single Minute Exchange of Die) para aumentar a eficiência da troca rápida de ferramentas e o uso de tecnologia de informação como suporte para o monitoramento do índice de desempenho dos equipamentos.

\section{REFERÊNCIAS}

BARNES, R.M. Estudo de movimentos e de tempos: projeto e medida de trabalho. 10. ed. São Paulo: Blucher, 2008.

CASSIA, M. T.; SILVA, R. P.; PAIXÃO, C. S. S.; BERTONHA, R. S.; CAVIOCHIOLI, F. A. Desgaste das facas do corte basal na qualidade da colheita mecanizada de cana-deaçúcar. Ciência Rural, Santa Maria, v.44, n.6, p. 987-993, jun. 2014.

CERVI, R. G.; ESPERANCINI, M. S. T.; SILVA, H. O. F.; ISLER, P. R.; OLIVEIRA, P. A. Avaliação do desempenho operacional da colheita e transbordo de cana-de-açúcar. Energia na Agricultura, v. 30, n.3, p. 232-241, 2015.

CHIARADIA, A. Utilização do indicador de eficiência global dos equipamentos na gestão de melhoria contínua dos equipamentos. Dissertação (Mestrado) - 
Universidade Federal do Rio Grande do Sul, Escola de Engenharia, Porto Alegre, RS, 2004.

COELHO, M. F. Planejamento da qualidade no processo de colheita mecanizada da cana-de-açúcar. 2009. 75f. Dissertação (Mestrado em Ciências) - Escola Superior de Agricultura "Luiz de Queiroz", Universidade de São Paulo, Piracicaba, 2009.

COMPANHIA NACIONAL DE ABASTECIMENTO. Acompanhamento de safra brasileira: cana-de-açúcar, segundo levantamento, agosto/2013. Brasília: Conab 2013.

FONTANA, G, SILVA, R. P. da; LOPES, A.; FURLANI, C. E. A. Avaliação das Características Ergonômicas no Posto do Operador em Colhedeiras Combinadas. In: CONGRESSO BRASILEIRO DE ENGENHARIA AGRÍCOLA, 41., Anais... ESALQ/USP, 2004, v. 24 , n. 3, p. 684-694.

GIACHINI, C. F. Desempenho operacional de uma colhedora de cana-de-açúcar (Saccharum spp.) em função dos turnos de trabalho. 2012. 57f. Dissertação (Mestrado em Agronomia, Energia na Agricultura) - Faculdade de Ciências Agronômicas, Universidade Estadual Paulista "Júlio de Mesquita Filho", Botucatu, 2012.

HANSEN, R. C. Eficiência global dos equipamentos: uma poderosa ferramenta de produção/manutenção para aumento dos lucros. Porto Alegre: Bookman, 2006.

KWON, O.; LEE, H. Calculation methodology for contributive managerial effect by OEE as a result of TPM activities. Journal of Quality in Maintenance Engineering, v. 10, n. 4 , p. 263-272, 2004.

MARQUES, T. A.; SASSO, C. G. A colheita da cana queimada e relação com o meio ambiente. Revista em Agronegócio e Meio Ambiente, v.3, n. 2, p.93-102, 2010.

MELLO, R. C. Influência do formato e velocidade da lâmina nas forças de corte para cana-de-açúcar. Acta Scientiarum Agronomy, Maringá, v. 27, n. 4, p. 661-665, oct./ dec., 2005.

MOLIN, J.P.; MILAN, M.; NESRALLAH, M.G.T.; CASTRO, C.N.; GIMENEZ, L.M.; Determinação de parâmetros de desempenho de colheita mecanizada utilizando dados do monitor de produtividade. In: CONGRESSO BRASILEIRO DE ENGENHARIA 
AGRÍCOLA, 32., 2003, Goiânia-GO. Anais.... Goiânia: SBEA, 2003.

NEVES, J. L. M.; MAGALHÃES, P. S. G.; OTA, W. M. Sistema de monitoramento de perdas visíveis de cana-de-açúcar em colhedora de cana picada. Engenharia Agrícola, Jaboticabal, v. 24, n. 3, p. 764-70, 2004.

RAMOS, C. R. G.; LANÇAS, K. P.; SANDI, J.; LYRA, G. A.; MILLANI, M. Qualidade do Corte dos Rebolos na Colheita Mecanizada da Cana-de-Açúcar em Diferentes Condições Operacionais. Revista Energia na Agricultura, v. 30. n. 3, p. 217-224, 2015.

RÍPOLI M.L.C, RÍPOLI T.C.C. Evaluation of five sugarcane planters. Engenharia Agrícola, v.30, n.6, p. 1110-1122, 2010.

RIPOLI, T. C. C.; RIPOLI, M.L.C. Biomassa de cana-de-açúcar: colheita, energia e ambiente. Piracicaba: Barros \& Marques, 302 p.2004.

SANTOS, A. C. O.; SANTOS, M. J. Utilização do indicador de Eficácia Global de Equipamentos (OEE) na gestão de melhoria contínua do sistema de manufatura. In: ENCONTRO NACIONAL DE ENGENHARIA DE PRODUÇÃO, 27., 2007, Foz de Iguaçu. Anais... Foz do Iguaçu: ENEGEP, 2007.

VOLPATO, J. L. M. Otimização de um cortador de base flutuante para seguimento do perfil de solo em colhedoras de cana-de-açúcar. 2001.204f. Tese (Doutorado em Engenharia Agrícola) - Faculdade de Engenharia Agrícola, Universidade Estadual de Campinas, 2001.

VOLTARELLI, M. A.; SILVA, R. P.; ZERBATO, C.; SILVA, V. F. A.; CAVICHIOLI, F. A. Agronomic capapility of mechanized sugarcane planting. Australian Journal of Crop Science, v. 8, n. 10, p. 1448-1460, 2014.

ZUASHKIANI, A.; RAHMANDAD, H.; JARDINE, A. Mapeando a dinâmica da eficácia global de equipamentos para aprimorar as práticas de gestão de activos. Journal of Quality em Engenharia de Manutenção, v. 17, n. 1, p. 74-92. 2011.

Recebido em: 25 de novembro de 2015 Aceito em: 06 de outubro de 2016 